\title{
Voting on the choice of core languages in the European Union
}

\author{
Jan Fidrmuc $^{a, b, c, *} \quad$ Victor Ginsburgh ${ }^{d} \quad$ Shlomo Weber ${ }^{b, e}$ \\ ${ }^{a}$ Department of Economics and Finance and Centre for Economic Development and \\ Institutions (CEDI), Brunel University, Uxbridge, UB8 3PH, United Kingdom. \\ ${ }^{b}$ CEPR, London, United Kingdom \\ ${ }^{c}$ WDI, University of Michigan, United States. \\ ${ }^{d}$ ECORE (CORE and ECARES), Université Libre de Bruxelles, C.P. 114, 50 Avenue F.D. \\ Roosevelt, 1050 Brussels, Belgium. \\ ${ }^{e}$ Department of Economics, Southern Methodist University, Dallas, TX 75248, United \\ States.
}

\begin{abstract}
Extensive multilingualism is one of the most important and fundamental principles of the European Union (EU). However, a large number of languages (currently 23) hinders communication and imposes substantial financial and legal costs. On the other hand, the reduction of the number of languages would disenfranchise some or many EU citizens. We use the results of a survey on languages and argue that even though a linguistic reform reducing the number of languages is unlikely to gain sufficient political support today, this may change in the future since young people are more proficient at speaking foreign languages.
\end{abstract}

JEL classification: D70, O52, Z13

Keywords: Languages, Disenfranchisement, European Union, Linguistic standardization

*Email: Jan.Fidrmuc@brunel.ac.uk or jan@fidrmuc.net. Phone: +44-1895-266-528, Fax: +44-1895-203-384. Web: http://www.fidrmuc.net/. 


\section{Introduction}

Linguistic diversity and its impact on public policies increasingly appear at the forefront of public debate in various countries and international organizations. Linguistic issues are almost unparalleled in terms of their patriotic and emotional appeal and, as was pointed out by Bretton (1976, p. 447), "language may be the most explosive issue universally and over time. This is mainly because language alone, unlike all other concerns associated with nationalism and ethnocentrism ... is so closely tied to the individual self. Fear of being deprived of communicating skills seems to raise political passion to a fever pitch."

The emergence of multilingual societies is well-documented over the course of the human history, but is by no means a thing of the past. The latest version of the Ethnologue database lists 6,912 distinct languages spoken all over the world. Since there are only 271 nations, dependencies and other entities, a large number of countries, if not most, must therefore be multilingual. Even though many of these nearly seven thousand languages are spoken in small and often remote and isolated communities, linguistic heterogeneity is wide-spread in today's world.

A functional multilingual society requires willingness on behalf of the participating linguistic groups to make compromises and to accept some linguistic standardization. This can, in turn, deliver important benefits in terms of improved communication, increased trade, better economic performance and enhanced administrative efficiency. Language standardization, however, restricts the linguistic rights of some groups; in line with Ginsburgh and Weber (2005) and Ginsburgh, Ortuño-Ortin and Weber (2005), we refer to this phenomenon as linguistic disenfranchisement. Note that the effect of curtailing the use of some languages goes beyond limiting access to information. Linguistic-minority members may feel that their language loses ground and they may in turn refrain from participating actively in the political process, or may even become unable to do so effectively. In the European context, EU laws take precedence over national legislation. Therefore the citizens' ability to receive information and to communicate in their own language has profound and direct implications on the economic and social fabric of the society and individual well-being.

Although English, French and, to a lesser extent, German are the languages used internally by the administration, all official communication between EU institutions and citizens of member countries or their government institutions as well as the sessions of the European Parliament are carried out in all 23 official languages. The same principle applies to all published legal documents of general application (such as regulations, directives or decisions addressed to member states) and to publications in the Official Journal. There are, however, provisions that allow the possibility that the Council of the European Union can, under special circumstances, legislate a restricted set of languages and that countries can voluntarily limit translation into their official language. The European Court also held that Art. 314 of the Treaty (on multilingualism and official languages) does not "enshrine 
an absolute Community law principle of the equality of all languages. [...] It follows that, because no absolute value attaches to the provisions of Art. 314, there will be circumstances where documents intended to produce legally binding effects can legitimately be drafted in some of the Community official languages only, which would then carry equal weight and authenticity as tools to interpret legislative intention." (Athanassiou, 2006, p. 11).

Our objective in this paper is to discuss the options for linguistic standardization as well as its likely political impact. At present, changes in the linguistic regime are subject to the unanimity rule although, given the provisions mentioned in the previous paragraph, such standardization is possible if approved by the Council. It is therefore important to examine the political support for such policies.

First, we assess the relative importance of European languages by examining disenfranchisement as reflected in linguistic proficiency (or the lack of thereof) of EU citizens. Our analysis is based on a unique, comprehensive and, to the best of our knowledge, previously unexplored survey dataset on languages and their use (Special Eurobarometer 255, 2006). We focus on disenfranchisement that would result if the full set of EU's 23 languages were limited to a more restrictive subset of core languages. Then we turn to examining subsets of official languages which could be supported by the Council of the EU under the application of qualified majority voting (QMV) as stipulated by the Nice and Lisbon Treaties. We show that the number of core languages would have to be relatively large: depending on the extent of linguistic disenfranchisement deemed as tolerable, between seven and eleven core languages would be required in order to meet all the currently applied Nice Treaty QMV criteria; application of the Lisbon Treaty would facilitate between five and eleven core languages. We also analyze the implications of Penrose's square root law under which every country is assigned a voting weight proportional to the square root of its population (see Penrose, 1946 and Laurelle and Widgren, 1998). The Penrose weight allocation represents the probability, that given a hypothetical vote in the European Council, the decision of a given country is decisive. The allocation has, therefore, been proposed in order to reflect an equal influence of every EU citizen on decisions of the European Council.

The paper is organized as follows. In Section 2 we discuss the notion of linguistic disenfranchisement. In Section 3 we use the provisions of the Nice and Lisbon Treaties to identify the sets of core languages sustainable under the possible application of Qualified Majority and examine the implications of the Penrose Law. Section 4 concludes.

\section{Linguistic disenfranchisement}

The challenges posed by the extensive multilingualism embraced by the EU (in particular the high cost of supporting 23 official languages and the practical difficulties related to ensuring high-quality translations and interpretation to and from multiple languages) necessitate a search for alternative 
solutions. Currently over 90 percent of the documents issued by the EU are drafted in English, French or German. Most of these are subsequently translated into some or all of the other official languages, including languages that have a small number of speakers or languages of populations that often are able to understand a language other than their own.

The choice of core languages should take into account the number of EU citizens who speak each language, including those outside of the native country of the language. The concept of linguistic disenfranchisement does this: it quantifies the number of citizens who would find themselves unable to communicate if their native language does not belong to the group of core languages and if they do not speak any of the core languages. Formally, let $\Lambda=\{1, \ldots, L\}$ be the current set of languages spoken in the EU. For any subset $T$ of $\Lambda$, disenfranchisement in country $k, d^{k}(T)$, can be defined as:

$$
d^{k}(T)=n^{k}-v^{k}(T)
$$

where $n^{k}$ is the population of country $k$ and $v^{k}(T)$ is the number of country $k$ 's citizens who speak at least one of the languages in $T$. To compare disenfranchisement across countries, it is convenient to express it in terms of disenfranchisement rates:

$$
D^{k}(T)=\frac{n^{k}-v^{k}(T)}{n^{k}}
$$

Table 1 exhibits the rates for the seven most widely spread languages in each EU member country. ${ }^{1}$ Note that if English were the only core language it would still leave 62.6 percent of EU's citizens disenfranchised, and there are only seven countries in which disenfranchisement would be below 50 percent.

\section{Insert Table 1.}

Young people often speak foreign languages more readily. We therefore report also EU-wide disenfranchisement rates for four age groups (15-29, 30-44, 45-59, over 60). The data show that English is the only language for which disenfranchisement rates are significantly lower among younger generations.

\section{Insert Table 2.}

Determining the set of official languages for a multilingual society entails, implicitly or explicitly, a cost-and-benefits analysis. The society must weigh the benefits of multilingualism against its costs. The latter go beyond the monetary costs of maintaining several parallel languages: communication is more cumbersome when speakers of different languages interact with each other, the

\footnotetext{
${ }^{1}$ The notion of disenfranchisement rate that we use is relatively strict: it comprises not only those who do not speak the language in question but also those who say that they only have a basic knowledge of it.
} 
need to translate official documents results in delays, and the costs due to misunderstanding or erroneous translations are important as well. However, if the costs depend only on the number of chosen languages, the search for an optimal linguistic regime boils down to achieving the lowest possible disenfranchisement with a given number of languages. The analysis that follows yields the subsets of languages that minimize disenfranchisement in this way. Let $m \leq L$ be a positive integer and for every $m \leq L$, denote by $T_{m}$ the subset of $\Lambda$ that minimizes the disenfranchisement rate over all sets with $m$ languages:

$$
D\left(T_{m}\right)=\min _{|T|=m} D(T),
$$

where $|T|$ denotes the number of languages in the set $T$.

The results of these computations are reproduced in Table $3 .^{2}$ Each column indicates which language should be added to the subset formed by the languages reported in the preceding columns so as to minimize disenfranchisement. Consider first the results in Panel A, where all respondents are taken into account. The optimal subset of one language contains English. For two languages, the optimal set contains English and German, and so on. ${ }^{3}$ The marginal contribution of each additional language to reducing disenfranchisement falls under one percent of the EU population once the number of languages exceeds 13 and the differences between marginal contributions attributable to the further candidate languages are often minute (to save space, we only report the first eleven languages). It is interesting to note also that the optimal sets computed according to equation (3) satisfy the sequencing principle so that every optimal set $T_{m}$ is a subset of the set $T_{m+1}$. In other words, there exists a sequence of languages $l_{1}, \ldots, l_{L}$ such that

$$
T_{m}=\left\{l_{1}, \ldots, l_{m}\right\}
$$

This simple observation allows us to present optimal sets in terms of sequences, where the switch from $T_{m}$ to $T_{m+1}$ is represented by adding a new language $l_{m+1}$ to the set $T_{m}$.

\section{Insert Table 3.}

English is clearly the first language and is spoken well or very well by one third of the EU population. German and French are in close race for the second position; German, with a 49.3 percent disenfranchisement rate, fares slightly better than French with 50.6 percent. This triple leads to a disenfranchisement rate of 37.8 percent. Italian, Spanish or Polish would each make almost the same contribution to reducing disenfranchisement further, with Italian slightly ahead of the other two languages. Spanish, in turn, performs only marginally better than Polish at the fifth position. With the six largest languages included, 16 percent of the EU population would still remain

\footnotetext{
${ }^{2}$ For further details on the calculation and additional results, see Fidrmuc et al. (2007).

${ }^{3}$ Note that there are instances where two languages result in approximately the same reduction in disenfranchisement at a particular step in the sequence. For example, the tenth language could be Czech or Greek. Taking Czech as the tenth language, Greek then appears again as the eleventh language.
} 
disenfranchised. Adding Romanian brings the residual disenfranchisement rate further down to 13 percent. Note that the addition of Italian, Polish and Romanian reduces disenfranchisement only because they are spoken as native languages by large domestic populations. Spanish is different since it is spoken also in some EU countries other than Spain (and it is also an international language spoken by large population groups in North, Central and South America).

Panel B presents an analogous sequence which only considers those respondents who are below 30 years of age. The sequence is very similar: the only difference is that French and German switch their positions. Note also that when considering only young respondents, the resulting disenfranchisement rates are substantially lower at every step. The marginal contribution from adding further languages falls below one percent once the sequence includes ten languages.

\section{Political Feasibility of Linguistic Reforms}

An examination of disenfranchisement rates and optimal sets presented in Table 3 shows that a unique core language will hardly be sufficient as it would yield a disenfranchisement rate of over 60 percent. Even the choice of English, French and German, the languages currently used by the EU administration, would leave a large fraction of the EU population (38 percent) disenfranchised (26 if we consider the young generation only). The decision on the set of core languages is inevitably a political one and boils down to deciding what extent of disenfranchisement is tolerable.

Traditionally, most EU decisions were made by unanimity. However, as the EU continued to expand, agreement by unanimity became increasingly difficult ${ }^{4}$ and therefore the EU has been gradually moving towards greater application of QMV, in particular with the adoption of the Single European Act in 1986. The Nice and Lisbon Treaties subsequently confirmed this trend. While this extended the range of issues for which qualified majority voting (QMV) is used, the EU language regime remains subject to the unanimity rule. As a result, Maltese and Estonian, at least in theory, enjoy the same status within the EU as Italian and Polish. This emphasis on national interests is understandable (and indeed unavoidable) given the institutional framework adopted by the EU and the tradition of unanimity. It is, however, also inherently undemocratic. In the context of linguistic policies, it implies that a Maltese or Estonian citizen weighs in more heavily than a Pole or Italian. Thus, in order to avoid that the EU becomes overwhelmed with dozens of languages and to enhance the democratic legitimacy of EU policies, the EU will have to shift the emphasis from national concerns to those of individual citizens.

Therefore, we now examine under which conditions a linguistic reform could pass under QMV rules stipulated by the Nice or the Lisbon Treaty. ${ }^{5}$ It is worth pointing out the voting rules under

\footnotetext{
${ }^{4}$ See, e.g., Baldwin et al. (2000, 2001) and Baldwin and Widgren (2004).

${ }^{5}$ Under the Nice Treaty, each member state has a fixed number of votes, with an EU-wide total of 345 . For a decision to pass, the following three requirements apply: (a) the proposal must backed by a majority of states (14 out of 27 ), (b) it must be supported by 255 out of the 345 votes, and (c) the states backing the votes must represent at least $62 \%$
} 
the Lisbon Treaty ${ }^{6}$ are exactly the same as under the previous draft of the European Constitution.

To discuss the possible variants of QMV, consider a setup with $K$ countries (members or potential members of the Union). Suppose that the union adopts a variant $Q$ of QMV which imposes a multicriteria restriction on the number and configuration of the countries required to support a decision. Denote the set of all coalitions of countries that satisfy $Q$ criteria by $C(Q)$.

Suppose also that each member $k$ of the Union chooses a maximum acceptable disenfranchisement rate $r_{k}, 0 \leq r_{k} \leq 1$ that serves as a threshold determining whether it would support a subset of core languages in $k$. Let the $r_{k}$ be given and let $R=\left(r_{1}, \ldots, r_{K}\right)$. The set of countries that accept the set $T$ given their chosen disenfranchisement rates $r_{k}$ and voting criteria $Q$, is

$$
W^{Q}(T, R)=\left\{k: D^{k}(T) \leq r_{k}\right\} .
$$

Obviously, the set $W^{Q}(T, R)$ is increasing with respect to inclusion and also with respect to vector $R$. That is, if $T \subset T^{\prime}$ then $W^{Q}(T, R) \subseteq W^{Q}\left(T^{\prime}, R\right)$ for every $R$. Likewise, for every set of languages $T$, $W^{Q}(T, R) \subseteq W^{Q}\left(T, R^{\prime}\right)$ whenever $r_{k} \leq r_{k}^{\prime}$ for every country $k$ in the union. The intuition is simple: an extension of the set of core languages $T$ and an increase of the disenfranchisement thresholds $R$, would (weakly) increase the number of countries supporting the choice of $\left(T^{\prime}, R^{\prime}\right)$.

Using the set of languages defined by equation (3), and given the vector of acceptable disenfranchisement rates $R$, define by $m^{*}(R)$ the minimal number of languages that guarantees that the set of countries $W^{Q}\left(T_{m^{*}(R)}, R\right)$ satisfies all $Q$ criteria:

$$
m^{*}(R)=\min \left\{m: W^{Q}\left(T_{m}, R\right) \in C(Q)\right\}
$$

The vector $R$ of acceptable disenfranchisement rates is computed as follows. We start with an acceptable average disenfranchisement rate $r$ ( $r$ takes the following values $0.10,0.20,0.30,0.40$ and 0.50) and modulate it according to the sensitivity of each country to linguistic issues. To estimate the countries' sensitivities, we use the percentage of citizens of a given country who tend to agree with the following statement (one of the questions in the Special Eurobarometer 255, 2006 survey): "The European institutions should adopt one single language to communicate with European citizens." These percentages $\rho_{k}$ are then normalized by the EU-wide weighted response to that question, denoted as $\rho$. The countries' rates $r_{k}$ are computed as

$$
r_{k}=r \frac{\rho_{k}}{\rho}, r=0.10, \ldots, 0.50
$$

and are reproduced in Table 4.

of the EU population (i.e. 303 million). Under the Lisbon Treaty for a decision to pass, it must be supported by $55 \%$ of the countries (15 out of 27 ) and by $65 \%$ of the EU population (318 million).

${ }^{6}$ The Lisbon Treaty will replace the Nice Treaty in 2014, if no member state raises any objection, or in 2017 if a member state requests a delay. 


\section{Insert Table 4.}

Table 5 presents the results of our calculations for the optimal sets based on all respondents (Panel A of Table 3), as well as on the young generation aged 15-29 only (Panel B of Table 3):

\section{Insert Table 5.}

Consider for instance the case in which all respondents are taken into account. Assume that the representatives of those countries for which the chosen set of languages results in an acceptable disenfranchisement rate that is on average smaller than or equal to 10 percent would vote for the proposal. Then, under the application of the Nice or Lisbon QMV rules, all of the eleven languages listed in Table 3 would be required for the reform to pass. The number of languages needed to pass a vote decreases as the acceptable average disenfranchisement rate increases, and it decreases faster under the Lisbon rules. The provision that is constraining in the case of the Nice Treaty is the fixed number of votes allocated to each country. This criterion is abandoned in the Lisbon Treaty, while the two remaining criteria are made somewhat stricter than those of the Nice Treaty (15 countries instead of 14 and 65 percent of the EU population instead of 62 percent). The combined effect leads nevertheless to a reduction in the number of core languages. Overall, the results show the following (under Lisbon QMV rules):

1. All respondents. A linguistic reform would be possible if it maintains between five (English, German, French, Italian, Spanish) and eleven (the previous ones plus Polish, Romanian, Hungarian, Portuguese, Czech and Greek) core languages as the acceptable average disenfranchisement rate goes from 50 to 10 percent.

2. Young generation aged 15-29 only. Between two (English, French) and nine (English, French, German, Italian, Spanish, Polish, Romanian, Hungarian and Portuguese) core languages would be required to make the reform politically feasible (again depending on the rate of acceptable disenfranchisement).

The provisions of both the Nice and the Lisbon Treaty assign relatively more voting power to large and small countries alike, while preventing middle-sized countries from receiving their fair share of power. This deficiency in assigning voting weights can be rectified by following the Penrose law which suggests that each country should be assigned a voting right proportional to the square root of its population. The Penrose weight allocation ensures an equal influence of every EU citizen on decisions of the European Council. In the last column of Table 5 we use Penrose weights and assume that a proposal that reaches 65 percent of the square root of EU's total population would pass. ${ }^{7}$

\footnotetext{
${ }^{7}$ We select the 65 percent threshold so that it is the same as that stipulated by the Lisbon Treaty. Alternatively, one can use a 62 percent threshold as suggested by Slomczynski, Zastawniak and Zyczkowski (2006) (the so-called Jagiellonian compromise).
} 
As can be seen, using Penrose's suggestion would allow restricting the number of core languages quite substantially. A regime with six core languages (English, French, German, Italian, Spanish and Polish) is likely to be accepted at a reasonably low twenty to thirty percent acceptable average disenfranchisement rate.

\section{Concluding Remarks}

Our analysis builds a formal framework to address the impact of extensive multilingualism in the EU. First, for any given number of languages, we determine the set of languages that minimizes linguistic disenfranchisement across the Union. This allows us to construct a nested sequence of core languages, in fact, a menu of possible choices for implementing a potential linguistic reform. It is very unlikely, however, that all 27 member states would be unanimous (as currently required by EU law) in their support for a reduction in the number of core languages, unless those populations whose languages are not part of the core language set are properly compensated.

We therefore compute the minimal number of core languages required under three alternative voting rules: the qualified-majority-voting provisions of the Nice Treaty and the Lisbon Treaty, and the Penrose law. It turns out that under the currently valid Nice QMV rules, the EU would need to maintain a rather large number of languages. It could reduce the set of offical languages to six, but only if some countries are ready to accept disenfranchisement rates as high as 50 percent. In the future, a more restrictive scenario with four to six languages might be feasible, since the Lisbon Treaty is somewhat less strict than the Nice Treaty, and the current young generation that will be decisive by then is more fluent in foreign languages (especially English). The core EU languages could then be English, French, German, Italian, Spanish and Polish.

The standardization scenarios that we suggest do not question the principle that all official languages would be used in the Parliament and in contacts between EU institutions and citizens. Importantly, however, linguistic standardization could stipulate that regulations and legal documents would be translated into a restricted number of languages (core languages) while the translation into other languages would be decentralized to countries that would be compensated for doing so, though only texts in core languages would be legally binding. ${ }^{8}$

Importantly, a linguistic reform, such as the one suggested in our paper, will change the incentives for acquiring skills in non-native languages. This will, in turn, change the dynamics of learning of foreign languages and further changes to the set of core languages should be feasible again later.

\section{Acknowledgements}

We are grateful to the associate editor and to two anonymous referees for their useful comments that improved the presentation of our results.

\footnotetext{
${ }^{8}$ See Fidrmuc and Ginsburgh (2007) for such a proposal and a discussion of its consequences.
} 


\section{Bibliography}

Athanassiou, P., 2006. The application of multilingualism in the European context. ECB Legal Working Paper No. 2, European Central Bank, Frankfurt.

Baldwin, R., Berglöf, E., Giavazzi F., Widgren M., 2000. EU reforms for tomorrow's Europe. CEPR Discussion Paper No. 2623, Centre for Economic Policy Research, London.

Baldwin, R., Berglöf E., Giavazzi F., Widgren M., 2001. Eastern enlargement and ECB reforms. Swedish Economic Policy Review 8, 15-50.

Baldwin, R., Windgrén M., 2004. Winners and losers under various dual majority rules for the EU Council of Ministers. CEPR Discussion Paper No. 4450, Centre for Economic Policy Research, London.

Bretton, H., 1976. Political science, language, and politics, in: O'Barr, W. M. and O'Barr, J. F. (Eds.), Language and Politics. Mouton, The Hague.

Fidrmuc, J., Ginsburgh, V. 2007. Languages in the European Union: The quest for equality and its cost. European Economic Review 51, 1351-1369.

Fidrmuc, J., Ginsburgh, V., Weber, S. 2007. Ever closer union or Babylonian discord? The officiallanguage problem in the European Union. CEPR Discussion Paper No. 636. Centre for Economic Policy Research, London.

Ginsburgh, V., Weber, S. 2005. Language disenfranchisement in the European Union. Journal of Common Market Studies 43, 273-286.

Ginsburgh, V., Ortuño-Ortin, I., Weber, S. 2005. Disenfranchisement in linguistically diverse societies. The case of the European Union. Journal of the European Economic Association 3, 946-965.

Laurelle, A., Widgren, M. 1998. Is the allocation of power among EU states fair? Public Choice 94, 317-339.

Penrose, L. 1946. The elementary statistics of majority voting. Journal of the Royal Statistical Society 109, 53-57.

Slomczynski, W., Zastawniak, T., Zyczkowski, K. 2006. The root of the matter: Voting in the EU Council. Physics World 19, 35-37.

Special Eurobarometer 255. 2006. Europeans and their languages. European Commission, Brussels. 
Table 1. Disenfranchisement in European Languages. Native and Foreign Languages Respondents with Basic or No Linguistic Skills (in \%)

\begin{tabular}{|c|c|c|c|c|c|c|c|}
\hline & English & German & French & Italian & Spanish & Polish & Dutch \\
\hline Austria & 55 & 1 & 94 & 95 & 98 & 100 & 100 \\
\hline Belgium & 59 & 87 & 29 & 97 & 97 & 99 & 32 \\
\hline Bulgaria & 84 & 94 & 96 & 99 & 99 & 100 & 100 \\
\hline Cyprus & 49 & 98 & 95 & 99 & 99 & 100 & 100 \\
\hline Czech Republic & 84 & 81 & 98 & 100 & 100 & 98 & 100 \\
\hline Denmark & 34 & 73 & 97 & 99 & 98 & 100 & 100 \\
\hline Estonia & 75 & 92 & 100 & 100 & 100 & 100 & 100 \\
\hline Finland & 69 & 95 & 99 & 100 & 100 & 100 & 100 \\
\hline France & 80 & 95 & 1 & 95 & 93 & 100 & 100 \\
\hline Germany & 62 & 1 & 92 & 99 & 98 & 98 & 100 \\
\hline Greece & 68 & 94 & 95 & 98 & 100 & 100 & 100 \\
\hline Hungary & 92 & 91 & 100 & 99 & 100 & 100 & 100 \\
\hline Ireland & 1 & 98 & 91 & 100 & 99 & 99 & 100 \\
\hline Italy & 75 & 96 & 90 & 3 & 97 & 100 & 100 \\
\hline Latvia & 85 & 97 & 100 & 100 & 100 & 99 & 100 \\
\hline Lithuania & 86 & 96 & 99 & 100 & 100 & 87 & 100 \\
\hline Luxemburg & 61 & 12 & 11 & 95 & 99 & 100 & 99 \\
\hline Malta & 32 & 99 & 95 & 65 & 99 & 100 & 100 \\
\hline Netherlands & 23 & 43 & 81 & 100 & 97 & 100 & 1 \\
\hline Poland & 82 & 90 & 99 & 99 & 100 & 2 & 100 \\
\hline Portugal & 85 & 98 & 91 & 99 & 96 & 100 & 100 \\
\hline Romania & 86 & 97 & 90 & 98 & 99 & 100 & 100 \\
\hline Slovak Republic & 83 & 82 & 99 & 100 & 100 & 98 & 100 \\
\hline Slovenia & 59 & 79 & 98 & 91 & 99 & 100 & 100 \\
\hline Spain & 84 & 98 & 94 & 99 & 2 & 100 & 100 \\
\hline Sweden & 33 & 88 & 97 & 99 & 99 & 100 & 100 \\
\hline United Kingdom & 1 & 98 & 91 & 99 & 98 & 100 & 100 \\
\hline EU27 & 62.6 & 75.1 & 80.1 & 86.7 & 88.9 & 91.6 & 95.1 \\
\hline
\end{tabular}


Table 2. Disenfranchisement rates

Age Groups (in \%)

\begin{tabular}{lccccc}
\hline & All & $15-29$ & $30-44$ & $45-60$ & $>60$ \\
\hline English & 61.2 & 43.2 & 57.3 & 66.6 & 74.3 \\
German & 73.7 & 72.6 & 74.0 & 74.3 & 74.0 \\
French & 79.4 & 77.1 & 79.8 & 79.6 & 80.5 \\
Italian & 86.0 & 86.3 & 85.9 & 85.7 & 86.3 \\
Spanish & 88.3 & 86.4 & 88.4 & 89.2 & 88.8 \\
Polish & 91.1 & 91.0 & 91.0 & 91.2 & 91.2 \\
Dutch & 94.8 & 94.7 & 94.8 & 94.8 & 94.9 \\
& & & & & \\
\hline
\end{tabular}


Table 3. Disenfranchisement rates (DR) in the Sequence of Optimal Sets (in \%)

\begin{tabular}{|c|c|c|c|c|c|c|c|c|c|c|c|}
\hline \multirow[t]{2}{*}{ A. All } & & 1 & 2 & 3 & 4 & 5 & 6 & 7 & 8 & 9 & $10 \mathrm{a}, \mathrm{b}$ \\
\hline & $\begin{array}{c}1 \\
\text { EN }\end{array}$ & $\begin{array}{c}2 \\
1+ \\
\mathrm{GE}\end{array}$ & $\begin{array}{c}3 \\
2+ \\
\text { FR }\end{array}$ & $\begin{array}{c}4 \\
3+ \\
\text { IT }\end{array}$ & $\begin{array}{c}5 \\
4+ \\
\text { SP }\end{array}$ & $\begin{array}{c}6 \\
5+ \\
\mathrm{PL}\end{array}$ & $\begin{array}{c}7 \\
6+ \\
\mathrm{RO}\end{array}$ & $\begin{array}{c}8 \\
7+ \\
\mathrm{HU}\end{array}$ & $\begin{array}{c}9 \\
8+ \\
\text { PT }\end{array}$ & $\begin{array}{c}10 \mathrm{a}, \mathrm{b} \\
9+ \\
\mathrm{CZ} \text { or GR }\end{array}$ & $\begin{array}{c}11 \\
9+ \\
\text { CZ \& GR }\end{array}$ \\
\hline DR & 62.6 & 49.3 & 37.8 & 29.5 & 22.4 & 16.4 & 12.9 & 10.9 & 9.2 & 7.7 & 6.2 \\
\hline \multirow[t]{2}{*}{ B. $\leq 30$} & & 1 & 2 & 3 & 4 & 5 & 6 & 7 & 8 & 9 & 10 \\
\hline & EN & $\begin{array}{c}2 \\
1+ \\
\text { FR }\end{array}$ & $\begin{array}{c}3 \\
2+ \\
\text { GE }\end{array}$ & $\begin{array}{c}4 \\
3+ \\
\text { IT }\end{array}$ & $\begin{array}{c}5 \\
4+ \\
\text { SP }\end{array}$ & $\begin{array}{c}6 \\
5+ \\
\text { PL }\end{array}$ & $\begin{array}{c}7 \\
6+ \\
\mathrm{RO}\end{array}$ & $\begin{array}{c}8 \\
7+ \\
\mathrm{HU}\end{array}$ & $\begin{array}{c}9 \\
8+ \\
\mathrm{PT}\end{array}$ & $\begin{array}{l}10 \\
9+ \\
\mathrm{CZ}\end{array}$ & DR \\
\hline DR & 44.6 & 34.5 & 25.8 & 19.9 & 14.4 & 10.4 & 7.8 & 6.3 & 5.1 & 3.9 & \\
\hline
\end{tabular}

Notes: One language is added in each column, as indicated in the second row. In some columns (e.g. 10a,b in Panel A), two languages result in approximately the same percentage reduction in disenfranchisement. Languages are abbreviated as follows: Czech (CZ), English (EN), French (FR), German (GE), Greek (GR), Hungarian (HU), Italian (IT), Spanish (SP), Polish (PL), Portuguese $(\mathrm{PT})$, Romanian (RO). Panel A considers all respondents, Panel B only those 30 years of age or younger. 
Table 4. Sensitivity of citizens to language issues

\begin{tabular}{lccccc}
\hline & $\begin{array}{c}\text { Answers }\left(\rho_{k}\right) \\
(1)\end{array}$ & $\begin{array}{c}\text { Sensitivity Index } \\
(2)\end{array}$ & & $\begin{array}{c}\text { Answers }\left(\rho_{k}\right) \\
(1)\end{array}$ & $\begin{array}{c}\text { Sensitivity Index } \\
(2)\end{array}$ \\
& & & & & \\
\hline Austria & 47 & 0.87 & Latvia & 58 & 1.07 \\
Belgium & 59 & 1.09 & Lithuania & 56 & 1.03 \\
Bulgaria & 34 & 0.63 & Luxemburg & 48 & 0.88 \\
Cyprus & 59 & 1.09 & Malta & 50 & 0.92 \\
Czech Rep. & 53 & 0.98 & Netherlands & 48 & 0.88 \\
Denmark & 44 & 0.81 & Poland & 69 & 1.27 \\
Estonia & 51 & 0.94 & Portugal & 50 & 0.92 \\
Finland & 36 & 0.66 & Romania & 46 & 0.85 \\
France & 51 & 0.94 & Slovak Rep. & 44 & 0.81 \\
Germany & 62 & 1.14 & Slovenia & 54 & 0.99 \\
Greece & 58 & 1.07 & Spain & 56 & 1.03 \\
Hungary & 65 & 1.20 & Sweden & 41 & 0.76 \\
Ireland & 44 & 0.81 & UK & 48 & 0.88 \\
Italy & 55 & 1.01 & EU $(\rho)$ & 54.3 & 1.00 \\
& & & & & \\
\hline
\end{tabular}

Column (1) reports percentages of citizens who that "tend to agree" with the following statement: "The European institutions should adopt one single language to communicate with European citizens." Column (2) is obtained by dividing these numbers by the weighted average for the overall $\mathrm{EU}(54.3 \%)$. 
Table 5. Voting scenarios. Minimal number of languages satisfying QMV

\begin{tabular}{|c|c|c|c|c|}
\hline & $\begin{array}{c}\text { Acceptable average } \\
\text { disenfranchisement rate }\end{array}$ & Nice Treaty & Lisbon Treaty & Penrose Law \\
\hline \multicolumn{5}{|l|}{ All } \\
\hline & 10 & 11 & 11 & 9 \\
\hline & 20 & 10 & 10 & 8 \\
\hline & 30 & 9 & 10 & 7 \\
\hline & 40 & 9 & 8 & 7 \\
\hline & 50 & 7 & 5 & 6 \\
\hline \multicolumn{5}{|l|}{$\leq 30$} \\
\hline & 10 & 9 & 9 & 7 \\
\hline & 20 & 7 & 5 & 6 \\
\hline & 30 & 7 & 5 & 6 \\
\hline & 40 & 5 & 3 & 4 \\
\hline & 50 & 4 & 2 & 3 \\
\hline
\end{tabular}

Nice: Approved if 255 votes, and 14 countries representing $62 \%$ of the population (303 million) vote for the reform

Lisbon: Approved, if 15 countries representing $65 \%$ of the population (318 million) vote for the reform

Penrose: Approved if $65 \%$ of the sum of the square roots of individual countries' populations vote for the reform 